\title{
BMJ Open Identification of stroke during the emergency call: a descriptive study of callers' presentation of stroke
}

\author{
Annika Berglund, ${ }^{1,2,3,4}$ Mia von Euler, ${ }^{1,2,3,4}$ Karin Schenck-Gustafsson, ${ }^{4,5}$ \\ Maaret Castrén, ${ }^{2}$ Katarina Bohm ${ }^{2,6}$
}

To cite: Berglund $A$, von Euler M, SchenckGustafsson $\mathrm{K}$, et al. Identification of stroke during the emergency call: a descriptive study of callers' presentation of stroke. BMJ Open 2015;5:e007661. doi:10.1136/bmjopen-2015007661

- Prepublication history for this paper is available online. To view these files please visit the journal online (http://dx.doi.org/10.1136/ bmjopen-2015-007661).

Received 13 January 2015 Revised 31 March 2015 Accepted 9 April 2015

CrossMark

For numbered affiliations see end of article.

Correspondence to

Annika Berglund;

annika.berglund@ki.se

\section{ABSTRACT}

Objectives: To evaluate symptoms presented by the caller during emergency calls regarding stroke, and to assess if symptoms in the Face-Arm-Speech-Time Test (FAST) are related to identification of stroke.

Setting: Emergency calls to the Emergency Medical Communication Center (EMCC) concerning patients discharged with stroke diagnosis in a large teaching hospital in Stockholm, Sweden, in January-June 2011. Participants: The emergency calls of 179 patients who arrived at hospital by ambulance, and who were discharged with a stroke diagnosis and consented to participate were included in the study.

Outcome measures: Frequencies of stroke symptoms presented and a comparison of symptoms presented in calls with dispatch code stroke or other dispatch code.

Results: Of the 179 emergency calls analysed, $64 \%$ were dispatched as 'Stroke'. FAST symptoms, that is, facial or arm weakness or speech disturbances, were presented in $64 \%$ of the calls and were spontaneously revealed in $90 \%$. Speech disturbance was the most common problem (54\%) in all calls, followed by fall/ lying position (38\%) and altered mental status (27\%). For patients with dispatch codes other than stroke, the dominating problem presented was a fall or being in a lying position (66\%), followed by speech disturbance $(31 \%)$ and altered mental status (25\%). Stroke-specific symptoms were more common in patients dispatched as stroke. FAST symptoms were reported in $80 \%$ of patients dispatched as stroke compared with $35 \%$ in those dispatched as something else.

Conclusions: This study implicates that fall/lying position and altered mental status could be considered as possible symptoms of stroke during an emergency call. Checking for FAST symptoms in these patients might uncover stroke symptoms. Future studies are needed to evaluate if actively asking for FAST symptoms in emergency calls presenting falls or a lying position can improve the identification of stroke. Trial registration number: Stroke2010/703-31/2.

\section{INTRODUCTION}

Treatment of acute ischaemic stroke is time critical and requires immediate initiation to

\section{Strengths and limitations of this study}

- The findings showed that mostly unspecific stroke symptoms were presented when the dispatch code was other than stroke and that fall or lying position was the dominating problem.

- The strength of the study is that authentic calls were analysed without the dispatcher or caller being aware of the study, and thus the study gives a view of real life situations.

- A limitation of the study is that only $57 \%$ of eligible patients consented to participate in the study. It is possible that severe stroke, dysphasia or limited knowledge of Swedish may have hindered patients' consenting to participation.

- Another limitation is that the patients with stroke mimics and transient ischaemic attacks were not included. Calls dispatched as stroke but not discharged from hospital as such could undoubtedly yield an interesting comparison but were not included in the study due to methodological issues.

restore circulation. ${ }^{1}$ As many patients with stroke arrive by ambulance, time to treatment can be decreased with high priority dispatch of ambulance if stroke is already identified from the Emergency Medical Communication Center (EMCC). ${ }^{2}$ Thus, identification of stroke during the emergency call is of great importance as delay can jeopardise the possibility of thrombolysis and vascular intervention.

Stroke identification by dispatchers during emergency calls has been shown to vary between $31 \%$ and $57 \% .^{3-8}$ Identifying stroke during an emergency call can be a challenge as the patient can neither be seen nor examined and the caller is usually a third person. ${ }^{9}$ To improve identification of stroke, different protocols are used in the prehospital setting. ${ }^{5}{ }^{10-16}$ One of the tests used to detect stroke is the Face-Arm-Speech-Time test (FAST), which is similar to the American Cincinnati Prehospital stroke scale. The test was developed for prehospital identification of 
stroke by checking for facial weakness, arm weakness and speech disturbances. ${ }^{14-16}$ FAST symptoms have been shown to be common in patients with stroke and the test is easy to perform for paramedics, physicians ${ }^{14} 1517$ and laypeople. ${ }^{18}$ Through lectures on stroke, the test was introduced to dispatchers and ambulance personnel in Stockholm in 2008, when preparing for another study on priority of stroke. ${ }^{19}$ Since then, FAST can be found under the heading 'Stroke' in the electronic criteria-based index, 'Medical Index', used by dispatchers.

A previous study from our group showed a positive predictive value of 56\% using FAST during emergency calls, which indicates limitations in identifying stroke using FAST by phone. ${ }^{19}$ In another study, it was shown that although FAST symptoms were noted in $27 \%$ of the medical records, FAST symptoms were mentioned during the initial emergency call in less than $5 \% .^{20}$ This implies that there is a need for more knowledge of how symptoms and findings of stroke are expressed during emergency calls, and raises the question of how FAST is used in the EMCC.

The aims of this study are to evaluate what findings callers present during an emergency call concerning stroke, if FAST symptoms are communicated and/or asked for, and if described FAST symptoms correlate to identification of stroke at the EMCC.

\section{MATERIALS AND METHODS}

This is a descriptive study of authentic emergency calls to the EMCC concerning patients with stroke in Stockholm, Sweden.

\section{Participants and setting}

The patients were recruited from a large teaching hospital with a catchment area of $\approx 600000$ inhabitants in Stockholm. Patients with a discharge diagnosis of stroke (International Classification of Diseases (ICD) 10 codes; I61, I63, I64) during January-June 2011 were identified from medical records and patients transported by ambulance to the hospital were eligible for the study.

In Stockholm, emergency calls are answered by call takers serving all emergency rescues. Health-related emergency calls are directed to nurses after relevant information such as address, condition of the patient, level of consciousness and breathing pattern has been obtained. The nurses summarise the complaint and the urgency in a predefined dispatch code associated to priority level. The ambulance is dispatched simultaneously. For support in evaluation and priority, the nurses can use an electronic criteria-based index of medical guidelines, the Medical Index. The Medical Index, containing 30 chapters, is mostly based on symptoms with some exceptions, for example, the stroke chapter. Thus, in order to be guided by the Medical Index, stroke needs to be suspected. There are no chapters describing unilateral weakness, facial weakness or speech disturbance. The guidelines recommend the highest priority (priority 1 ) for patients with suspected stroke and symptom onset within $6 \mathrm{~h}$. The priority ranges from 1 to 4 where priority 1 indicates immediate dispatch and is used for lifethreatening conditions.

\section{Data collection}

A data collection tool was used to retrospectively document the findings from recorded emergency calls. The recordings of the emergency calls were listened to repeatedly by $\mathrm{AB}$ and the findings were transferred to the data collecting tool.

The data colleting tool was developed by $\mathrm{AB}$ and $\mathrm{KB}$ through discussion and listening to 10 emergency calls; the tool included the first mentioned problem, described FAST symptoms and other presented symptoms. Additional data, such as priority, diagnosis and treatment, were retrieved from EMCC data and hospital medical records. In the data collection tool, lying position was added to fall, as a lying position may indicate an unwitnessed fall and inability to stand up due to stroke symptoms, and is therefore relevant. For the same reason, problems in walking were added to leg weakness.

\section{Statistical analysis}

Descriptive statistics are presented in frequencies and proportions with calculation using SPSS Statistics, V.22 (IBM Corporation 2010, Route 100, Somer, New York 10589, USA). For categorical data, the Fisher exact test was used to test significance. The $95 \%$ CI was calculated. $^{21}$

\section{Ethical consideration}

The study was registered at http://www.clinicaltrials.gov, protocol ID; Stroke2010/703-31/2. The patients or their relatives were asked for consent to participate in the study, orally or by letter, in Swedish.

All patients received written information on the study and its purpose, and were notified that participation was voluntary, with patients having the right to terminate participation at any point without providing a reason. The consent included permitting the reading of medical records from the hospital and the ambulance, and allowing the recording of the authentic emergency call to be listened to. Consent to listen to the emergency calls was also obtained from the EMCC.

\section{RESULTS}

During the study period, 428 patients arriving at hospital by ambulance and discharged with a stroke diagnosis were identified and asked to participate in the study. Consent was given by 245 patients $(57 \%)$. Of these, 66 patients were excluded as their calls were not direct calls to the EMCC (figure 1).

Finally, 179 patients were included in the study. Patients' characteristics and background data are described in table 1 . Median age was 79 years (26-97 minimum/maximum). In $85 \% \quad(n=152)$, the patients' 
Figure 1 Flow chart over study recruitment (EMCC, Emergency Medical Communication Center).

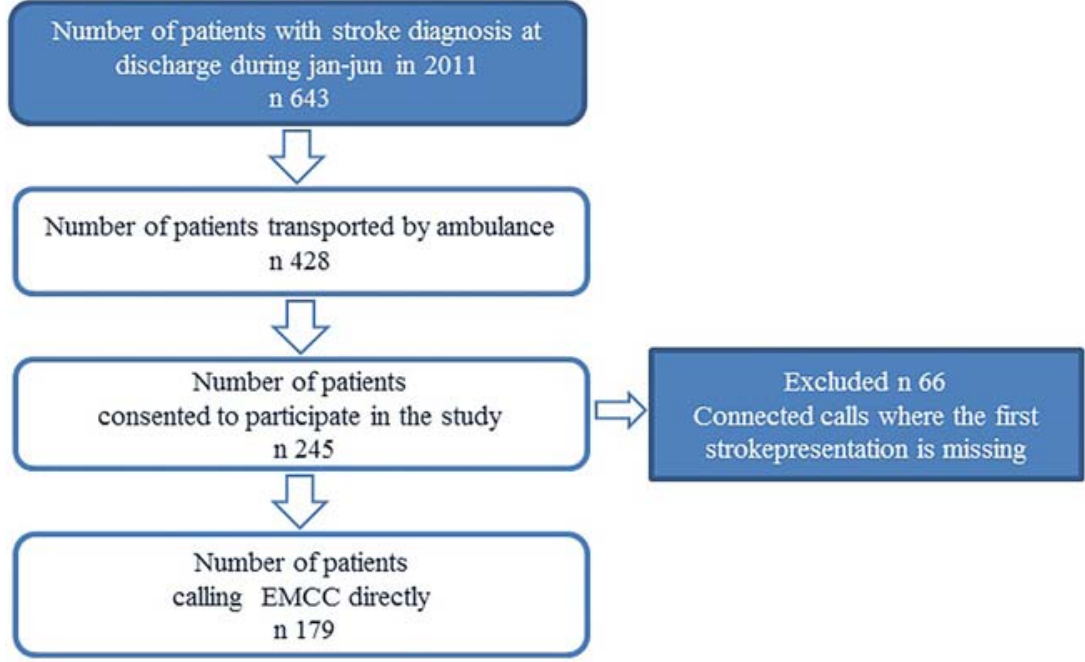

diagnosis was ischaemic stroke and in 15\% ( $\mathrm{n}=27)$, intracerebral haemorrhage. An ambulance was dispatched with priority 1 in $64 \%$ of all calls (table 1 ). For patients with recorded symptom onset within $6 \mathrm{~h}$, an ambulance was dispatched with priority 1 to $89 \%$ of patients. For patients with symptom onset after the $6 \mathrm{~h}$ window, an ambulance was dispatched with priority 1 to $43 \%$ of patients.

\section{Symptoms presented}

Speech disturbance was the most frequently presented problem $(54 \%)$, followed by fall or lying position $(38 \%)$ and altered mental status (27\%; table 2). Suspicion of stroke was mentioned by the caller in 87 of the calls (49\%; table 1) and coded 'Stroke' in $66(76 \%)$ of these. The remaining 21 calls coded non-stroke presented symptoms and were prioritised similarly to the rest of the calls coded non-stroke without suspicion of stroke by the caller. At least one FAST symptom was presented in $64 \%$ of all calls and was presented spontaneously by the caller in $90 \%$ of those. A FAST symptom was mentioned by the caller first in the conversation in $35 \%$ of all calls.

\section{Patients coded as 'Stroke'}

Stroke-specific symptoms were more commonly presented in the calls coded as 'Stroke' (table 2). A FAST symptom was presented in $80 \%$ of the calls and the most noted problem was speech disturbance (68\%). In addition to stroke-specific symptoms, altered mental status $(29 \%)$ and fall or lying position $(22 \%)$ were commonly presented (table 2). Unconsciousness was described in $4 \%$ of the patients coded as stroke. Most

\begin{tabular}{|c|c|c|c|c|c|c|}
\hline & $\begin{array}{l}\text { Total \% } \\
\text { (n 179) }\end{array}$ & $\mathrm{Cl}(\%)$ & $\begin{array}{l}\text { Dispatch code } \\
\text { 'Stroke' \% (n 114) }\end{array}$ & $\mathrm{Cl}(\%)$ & $\begin{array}{l}\text { Other dispatch } \\
\text { code } \% \text { (n 65) }\end{array}$ & $\mathrm{Cl}(\%)$ \\
\hline Men & 49 (87) & 41 to 56 & $46(52)$ & 36 to 55 & $54(35)$ & 42 to 66 \\
\hline Women & $51(92)$ & 42 to 56 & $54(62)$ & 45 to 64 & $46(30)$ & 34 to 58 \\
\hline \multicolumn{7}{|l|}{ Dispatch priority } \\
\hline 1 & $64(115)$ & 57 to 71 & $70(80)$ & 62 to 79 & $54(35)$ & 42 to 66 \\
\hline 2 & $31(55)$ & 24 to 38 & $27(31)$ & 19 to 35 & $37(20)$ & 25 to 49 \\
\hline 3 & $5(9)$ & 2 to 8 & $3(3)$ & 0 to 6 & $9(6)$ & 2 to 16 \\
\hline \multicolumn{7}{|l|}{ Time of onset } \\
\hline$<6 \mathrm{~h}$ & $46(82)$ & 38 to 53 & $54(61)$ & 44 to 63 & $32(21)$ & 21 to 44 \\
\hline$>6 \mathrm{~h}$ & $26(47)$ & 20 to 31 & $24(27)$ & 16 to 32 & $31(20)$ & 20 to 42 \\
\hline Unknown & $28(50)$ & 21 to 34 & $23(26)$ & 15 to 30 & $37(24)$ & 25 to 49 \\
\hline \multicolumn{7}{|l|}{ Caller (unknown in 2 calls) } \\
\hline Relative & $48(86)$ & 41 to 55 & $49(56)$ & 40 to 58 & $46(30)$ & 34 to 58 \\
\hline Healthcare provider & $23(42)$ & 17 to 30 & $24(27)$ & 16 to 32 & $23(15)$ & 13 to 33 \\
\hline Other & $16(29)$ & 12 to 23 & $13(15)$ & 7 to 19 & $22(14)$ & 12 to 32 \\
\hline Patient & $11(20)$ & 7 to 16 & $13(15)$ & 7 to 19 & $8(5)$ & 1 to 14 \\
\hline The callers suspect stroke & 49 (87) & 41 to 56 & $58(66)$ & 49 to 67 & $32(21)$ & 21 to 44 \\
\hline Thrombolytic treatment & $18(32)$ & 12 to 24 & $24(27)$ & 16 to 32 & $8(5)$ & 1 to 14 \\
\hline
\end{tabular}


Table 2 Symptoms revealed during the emergency call, from the call taker and the nurse

\begin{tabular}{|c|c|c|c|c|c|c|c|}
\hline & $\begin{array}{l}\text { Total \% } \\
\text { (n 179) }\end{array}$ & $\mathrm{Cl}(\%)$ & $\begin{array}{l}\text { Dispatch } \\
\text { code } \\
\text { 'Stroke' \% } \\
\text { (n 114) } \\
\end{array}$ & $\mathrm{Cl}(\%)$ & $\begin{array}{l}\text { Other } \\
\text { dispatch } \\
\text { code \% } \\
\text { (n 65) }\end{array}$ & $\mathrm{Cl}(\%)$ & $\begin{array}{l}\text { Fischer's } \\
\text { exact } \\
\text { test } \\
\text { p value }\end{array}$ \\
\hline Facial weakness, FAST & $16(29)$ & 11 to 22 & $25(28)$ & 17 to 32 & $2(1)$ & 2 to 4 & $<0.001$ \\
\hline Arm weakness, FAST & $15(27)$ & 10 to 20 & $21(24)$ & 14 to 28 & $5(3)$ & 1 to 10 & 0.002 \\
\hline Speech disturbance, FAST & $54(97)$ & 47 to 62 & $68(77)$ & 59 to 76 & $31(20)$ & 20 to 42 & $<0.001$ \\
\hline $\begin{array}{l}\text { Leg weakness/trouble } \\
\text { walking }\end{array}$ & $20(35)$ & 14 to 25 & $24(27)$ & 16 to 32 & $12(8)$ & 4 to 20 & NS \\
\hline Unilateral symptoms & $16(29)$ & 11 to 22 & $23(26)$ & 15 to 30 & $5(3)$ & 1 to 10 & 0.001 \\
\hline Numbness/sensory loss & $9(16)$ & 5 to 13 & $13(15)$ & 7 to 19 & $2(1)$ & 0 to 4 & 0.012 \\
\hline Hand weakness & 7 (12) & 3 to 10 & $10(11)$ & 4 to 15 & $2(1)$ & 0 to 4 & NS \\
\hline Impaired vision & $3(5)$ & 0 to 5 & $2(2)$ & 0 to 4 & $5(3)$ & 0 to 10 & NS \\
\hline Unsteadiness/poor balance & $6(11)$ & 3 to 10 & $8(9)$ & 3 to 13 & $3(2)$ & 0 to 7 & NS \\
\hline Dizziness & $8(14)$ & 4 to 12 & $9(10)$ & 4 to 14 & $6(4)$ & 0 to 12 & NS \\
\hline Nausea/vomiting & $8(14)$ & 4 to 12 & $8(9)$ & 3 to 13 & $8(5)$ & 1 to 14 & NS \\
\hline Headache & $9(16)$ & 5 to 13 & $10(11)$ & 4 to 15 & $8(5)$ & 1 to 14 & NS \\
\hline Altered mental status & 27 (49) & 21 to 34 & $29(33)$ & 21 to 37 & $25(16)$ & 14 to 35 & NS \\
\hline Fall/lying position & $38(68)$ & 31 to 45 & $22(25)$ & 14 to 30 & $66(43)$ & 55 to 78 & $<0.001$ \\
\hline
\end{tabular}

The symptoms are divided between the calls with dispatch code 'Stroke' and the calls with dispatch codes other than stroke. NS, non-significant.

patients with symptom onset within $6 \mathrm{~h}$ were coded 'Stroke' (74\%), and ambulance was dispatched with priority 1 in $81 \%$ of those patients with symptom onset within $6 \mathrm{~h}$, and dispatched as stroke.

\section{Patients coded as other than stroke}

Among calls coded as other than stroke, the most common code was 'Uncertain data/seriously ill patient' $(52 \%)$ and half of those calls were dispatched with priority 1 (table 3 ). As presented in table 2 , fall or lying position $(66 \%)$ was the most frequently presented problem followed by speech disturbance $(31 \%)$ and altered mental status $(25 \%)$. FAST symptoms $(35 \%)$ were presented less in these calls. Unconsciousness was reported in $25 \%$, all dispatched as priority 1 . Of the non-stroke dispatched calls, 32\% were reported with onset within $6 \mathrm{~h}$, and an ambulance was dispatched with priority 1 in $67 \%$ of the non-stroke dispatched calls with onset within $6 \mathrm{~h}$.

\section{Sex differences}

Women were older, median age 83 vs 74 years for men. The reported symptoms were similar except for altered mental status, which was more frequently reported in women $(36 \%)$ than in men $(18 \% ; \mathrm{p}=0.012)$.

Thrombolytic treatment was given to $21 \%$ of the patients with ischaemic stroke, $16 \%$ and $27 \%$ in women and men, respectively. Women treated with thrombolysis were older, median age 81 years for women compared with 65 years for men $(p=0.001)$. Most callers were relatives of the patients, in $53 \%$ and $44 \%$ of male and female patients, respectively, or a healthcare provider, in $10 \%$ and $36 \%$ of male and female patients, respectively.

Table 3 An overview of the dispatch codes, in numbers, and the dispatch priority of the calls in the study

\begin{tabular}{|c|c|c|c|c|}
\hline Dispatch code & Priority 1 & Priority 2 & Priority 3 & Total \\
\hline Stroke & 80 & 31 & 3 & 114 \\
\hline Uncertain data/seriously ill patient & 17 & 15 & 2 & 34 \\
\hline Unconsciousness & 10 & - & - & 10 \\
\hline Extremity & - & 5 & 1 & 6 \\
\hline Seizure & 3 & - & - & 3 \\
\hline Headache/dizziness & 1 & - & 2 & 3 \\
\hline Diabetes & 2 & - & - & 2 \\
\hline Breathing difficulties/problem & 1 & 1 & - & 2 \\
\hline Chest pain/heart disease & 1 & - & 1 & 2 \\
\hline Urgent need of care & - & 1 & - & 1 \\
\hline Suspected suicide/psychiatry & - & 1 & - & 1 \\
\hline Abdominal/urinary tract & - & 1 & - & 1 \\
\hline Total & 115 & 55 & 9 & 179 \\
\hline
\end{tabular}




\section{DISCUSSION}

In this descriptive analysis of emergency calls concerning patients with stroke, we found that a FAST symptom, that is, facial weakness, arm weakness or speech disturbance, was mentioned first in one-third of the calls. If a FAST symptom was mentioned, as it was in $64 \%$ of the calls, it was almost always spontaneously presented. We found that identification of stroke in emergency calls was more common in patients with one or more FAST symptoms. However, the presence of FAST symptoms was not synonymous with an identification of stroke, which was obvious from the finding that in 1/3 of calls coded as non-stroke, FAST symptoms were expressed. Presentation of FAST symptoms is not unique for stroke, which has previously been reported in emergency calls of non-stroke. ${ }^{62}$ In one of our previous studies, FAST symptoms were reported in $50 \%$ of the emergency calls with non-stroke diagnoses. ${ }^{19}$ It has to be noted that FAST was constructed based on data from medical records and physical examinations of patients with stroke prehospital and at hospital. ${ }^{10} 1417$ When used in emergency calls, this study shows that if FAST symptoms are not obvious to the caller and mentioned the EMCC, dispatcher rarely asks for them.

An interesting finding in this study was the high frequency of fall or lying position presented and that this dominated the calls when stroke was not identified. In previous studies, fall or collapse has been reported as the first mentioned problem in $26 \%,{ }^{20}$ and as the main problem in $21 \%$, in the emergency calls of patients with stroke. ${ }^{23} \mathrm{~A}$ fall can be a consequence of stroke but a fall is also a common problem among elderly people in general. ${ }^{24}$ In a British study, falls were reported as the reason for emergency calls in $8 \% .{ }^{25}$ In a study comparing stroke calls to non-stroke calls, fall/collapse was found to dominate in the stroke calls in $38 \%$, and was present in $26 \%$ of the non-stroke calls. ${ }^{22}$ Another study showed falls to be a factor increasing the risk of misdiagnosing stroke. ${ }^{8}$ This is confirmed in our present study, and the risk seems particularly high if a combination of fall/lying position and less typical stroke symptoms are presented.

Previous study results vary according to sex differences in symptoms of stroke. When evaluating presence of symptoms in the clinic, no differences were detected, ${ }^{26}$ but in interviews, females have presented significantly more non-traditional stroke symptoms. ${ }^{27}{ }^{28}$ Our results are in concordance with a study finding altered mental status to be significantly more frequent in female patients. ${ }^{28}$ As this is a non-specific symptom, stroke is less often suspected.

Altered mental status was another non-specific stroke symptom commonly expressed in the calls and was also previously reported to be a frequent symptom from patients in the emergency department, where $28 \%$ had a neurological aetiology. ${ }^{29}$ A previous study reported altered mental status to be one of several symptoms of patients with stroke not identified as stroke in hospital. ${ }^{30}$
Presentations of altered mental status and falls are common symptoms in emergency calls, ${ }^{24}{ }^{29}$ and generally not acknowledged as symptoms of stroke. However, altered mental status might reflect symptoms such as speech disturbance, neglect or apraxia, which are stroke-specific symptoms but may be difficult to identify for a layman.

In this study, the dispatchers coded stroke in $64 \%$ of the stroke calls, which is comparable to the results of a recent study. ${ }^{8}$ It has been shown that mentioning of a suspicion of stroke by the caller has a strong association to stroke diagnosis. ${ }^{10} 2022$ In view of that, it is notable that in one of four calls in our study, where suspicion of stroke was mentioned by the caller, no code of stroke was given by the dispatching nurse.

Priority in acute stroke is of the essence, as thrombolysis and thrombectomy depend on fast identification. ${ }^{131}$ The calls with dispatch codes other than stroke were less highly prioritised, $54 \%$ compared with $70 \%$ of the calls dispatched as stroke. The ambulance dispatch risks delay when stroke is not identified during an emergency call. $^{2} 2032$ Time of symptom onset was also noted as unknown more frequently in patients coded as nonstroke and probably reflects that time of onset was not asked for if stroke was not suspected.

A limitation of this study is the $57 \%$ participation rate. Ethical concerns hindered analyses of the nonparticipants and it is possible that severe stroke, dysphasia or limited knowledge of Swedish could have hindered patients' consenting to participation. However, the findings are similar to other studies of emergency calls concerning stroke. ${ }^{3} 681920222333$

\section{CONCLUSION}

The presence of FAST in the calls identified as stroke demonstrates advantages of the test. However, FAST symptoms were found to be present but not recognised in many calls coded as non-stroke. Almost all FAST symptoms were spontaneously reported by the caller. To increase the identification of stroke, the results imply that if fall/lying position or altered mental status are presented during the emergency call, the dispatcher should check for stroke, for example, by FAST test. Also, the callers' suspicion of stroke should be a strong indicator for stroke during the emergency call.

\section{Author affiliations}

${ }^{1}$ Karolinska Institutet Stroke Research Network at Södersjukhuset, Stockholm, Sweden

${ }^{2}$ Department of Clinical Science and Education, Karolinska Institutet, Södersjukhuset, Stockholm, Sweden

${ }^{3}$ Section of Neurology, Department of Internal Medicine, Södersjukhuset, Stockholm, Sweden

${ }^{4}$ Karolinska Institutet, Center for Gender Medicine, Stockholm, Sweden

${ }^{5}$ Department of Medicine, Karolinska Institutet, Stockholm, Sweden

${ }^{6}$ Section of Emergency Medicine, Södersjukhuset, Stockholm, Sweden

Acknowledgements The authors are grateful for the support and cooperation of the personnel at SOS Alarm AB in Stockholm and Lina Benson at Karolinska Institutet, Department of Clinical Science and Education, Södersjukhuset, for statistical discussion. 
Contributors $\mathrm{AB}, \mathrm{MvE}, \mathrm{MC}$ and $\mathrm{KB}$ contributed with design, analysis and drafting the result. $A B$ collected data. KS-G contributed with the design and drafting of the result. All authors approved publication of the paper and agree to be accountable for all aspects of the work in ensuring that questions related to the accuracy or integrity of any part of the work are appropriately investigated and resolved.

Funding Financial support was provided through the Erika Lederhausen Foundation for Center for Gender Medicine, Karolinska Institutet, the foundation for Women and Health (Stiftelsen Kvinnor och Hälsa), the Swedish Stroke Association and from the regional agreement on medical training and clinical research (A.L.F.) between the Stockholm County Council and Karolinska Institutet and Falck foundation. This study is part of the Fighting Stroke Project (Uppdrag Besegra Stroke) supported by the Swedish Heart and Lung Foundation, and Karolinska Institutet; funding from Friends of Karolinska Institutet, USA, and Johanniterorden, supports the project.

Competing interests None declared.

Ethics approval Regional Ethics Board (EPN:2010/703-31/2 and 13-2010).

Provenance and peer review Not commissioned; externally peer reviewed.

Data sharing statement No additional data are available.

Open Access This is an Open Access article distributed in accordance with the Creative Commons Attribution Non Commercial (CC BY-NC 4.0) license, which permits others to distribute, remix, adapt, build upon this work noncommercially, and license their derivative works on different terms, provided the original work is properly cited and the use is non-commercial. See: http:// creativecommons.org/licenses/by-nc/4.0/

\section{REFERENCES}

1. Wardlaw JM, Murray V, Berge E, et al. Recombinant tissue plasminogen activator for acute ischaemic stroke: an updated systematic review and meta-analysis. Lancet 2012;379:2364-72.

2. Berglund A, Svensson L, Sjostrand C, et al. Higher prehospital priority level of stroke improves thrombolysis frequency and time to stroke unit: the Hyper Acute STroke Alarm (HASTA) study. Stroke 2012;43:2666-70.

3. Rosamond WD, Evenson KR, Schroeder EB, et al. Calling emergency medical services for acute stroke: a study of 9-1-1 tapes. Prehosp Emerg Care 2005;9:19-23.

4. Buck BH, Starkman S, Eckstein M, et al. Dispatcher recognition of stroke using the National Academy Medical Priority Dispatch System. Stroke 2009;40:2027-30.

5. Studnek JR, Asimos A, Dodds J, et al. Assessing the validity of the Cincinnati Prehospital Stroke Scale and the medic prehospital assessment for code stroke in an Urban Emergency Medical Services Agency. Prehosp Emerg Care 2013;17:348-53.

6. Krebes S, Ebinger M, Baumann AM, et al. Development and validation of a dispatcher identification algorithm for stroke emergencies. Stroke 2012;43:776-81.

7. Deakin CD, Alasaad M, King $P$, et al. Is ambulance telephone triage using advanced medical priority dispatch protocols able to identify patients with acute stroke correctly? Emerg Med J 2009;26:442-5.

8. Chenaitia $\mathrm{H}$, Lefevre $\mathrm{O}, \mathrm{Ho} \mathrm{V}$, et al. Emergency medical service in the stroke chain of survival. Eur J Emerg Med 2013;20:39-44.

9. Karlsten R, Elowsson P. Who calls for the ambulance: implications for decision support. A descriptive study from a Swedish dispatch centre. Eur J Emerg Med 2004;11:125-9.

10. Whiteley WN, Wardlaw JM, Dennis MS, et al. Clinical scores for the identification of stroke and transient ischaemic attack in the emergency department: a cross-sectional study. J Neurol Neurosurg Psychiatry 2011;82:1006-10.

11. Kidwell CS, Starkman S, Eckstein M, et al. Identifying stroke in the field. Prospective validation of the Los Angeles Prehospital Stroke Screen (LAPSS). Stroke 2000;31:71-6.

12. Frendl DM, Strauss DG, Underhill BK, et al. Lack of impact of paramedic training and use of the Cincinnati Prehospital Stroke Scale on stroke patient identification and on-scene time. Stroke 2009;40:754-6.

13. Bray JE, Martin J, Cooper G, et al. An interventional study to improve paramedic diagnosis of stroke. Prehosp Emerg Care 2005;9:297-302.

14. Harbison J, Hossain O, Jenkinson D, et al. Diagnostic accuracy of stroke referrals from primary care, emergency room physicians, and ambulance staff using the face arm speech test. Stroke 2003;34:71-6

15. Nor AM, McAllister C, Louw SJ, et al. Agreement between ambulance paramedic- and physician-recorded neurological signs with Face Arm Speech Test (FAST) in acute stroke patients. Stroke 2004;35:1355-9.

16. Kothari RU, Pancioli A, Liu T, et al. Cincinnati Prehospital Stroke Scale: reproducibility and validity. Ann Emerg Med 1999;33:373-8.

17. Goldstein LB, Simel DL. Is this patient having a stroke? JAMA 2005;293:2391-402.

18. Nationella Strokekampanjen. Secondary Nationella Strokekampanjen 2014-01-22. 2014. http://strokekampanjen.se/

19. Berglund A, Svensson L, Wahlgren N, et al. Face arm speech time test use in the prehospital setting, better in the ambulance than in the emergency medical communication center. Cerebrovasc Dis 2014;37:212-16.

20. Jones SP, Carter B, Ford GA, et al. The identification of acute stroke: an analysis of emergency calls. Int J Stroke 2013;8: 408-12.

21. Gardner MJ, Altman DG. Statistics with confidence: confidence intervals and statistical guidelines. London: British Medical Journal, 1989.

22. Leathley MJ, Jones SP, Gibson JM, et al. "Can you send an ambulance please?" A comparison of callers' requests for emergency medical dispatch in non-stroke and stroke calls. Emerg Med J 2013;31:e25-8.

23. Handschu R, Poppe R, Rauss J, et al. Emergency calls in acute stroke. Stroke 2003;34:1005-9.

24. Rubenstein LZ. Falls in older people: epidemiology, risk factors and strategies for prevention. Age Ageing 2006;35(Suppl 2):ii37-41.

25. Snooks HA, Halter M, Close JC, et al. Emergency care of olde people who fall: a missed opportunity. Qual Saf Health Care 2006;15:390-2.

26. Barrett KM, Brott TG, Brown RD Jr, et al. Sex differences in stroke severity, symptoms, and deficits after first-ever ischemic stroke. $J$ Stroke Cerebrovasc Dis 2007;16:34-9.

27. Labiche LA, Chan W, Saldin KR, et al. Sex and acute stroke presentation. Ann Emerg Med 2002;40:453-60.

28. Lisabeth LD, Brown DL, Hughes R, et al. Acute stroke symptoms: comparing women and men. Stroke 2009;40:2031-6.

29. Kanich W, Brady WJ, Huff JS, et al. Altered mental status: evaluation and etiology in the ED. Am J Emerg Med 2002;20:613-17.

30. Dupre CM, Libman R, Dupre SI, et al. Stroke chameleons. J Stroke Cerebrovasc Dis 2013;23:374-8.

31. Berkhemer OA, Fransen PS, Beumer D, et al. A randomized trial of intraarterial treatment for acute ischemic stroke. $N$ Engl J Med 2015;372:11-20.

32. Caceres JA, Adil MM, Jadhav V, et al. Diagnosis of stroke by emergency medical dispatchers and its impact on the prehospital care of patients. J Stroke Cerebrovasc Dis 2013;22:e610-14.

33. Mosley I, Nicol M, Donnan G, et al. Stroke symptoms and the decision to call for an ambulance. Stroke 2007;38:361-6. 